\title{
Dinheiro e Conjugalidade: Uma Revisão Sistemática da Literatura
}

\author{
Cláudia Mara Bosetto Cenci ${ }^{1}$ \\ Programa de Pós-Graduação em Psicologia Clínica da Pontifícia Universidade Católica \\ do Rio Grande do Sul, Porto Alegre, RS, Brasil \\ Faculdade Meridional - IMED, Passo Fundo, RS, Brasil \\ Camila Scomazzon Bona \\ Pamela Letícia Crestani \\ Pontifícia Universidade Católica do Rio Grande do Sul, Porto Alegre, RS, Brasil \\ Luisa Fernanda Habigzang \\ Programa de Pós-Graduação em Psicologia da Pontificia Universidade Católica \\ do Rio Grande do Sul, Porto Alegre, RS, Brasil
}

\section{Resumo}

Este artigo objetivou realizar uma revisão sistemática da literatura nacional e internacional da produção científica existente sobre a temática dinheiro e conjugalidade no período de 2004 a 2014 . Foram consultadas as bases de dados PsycINFO, Scientific Electronic Library Online (SciELo), Periódicos Eletrônicos de Psicologia (PePSIC) e Periódicos Capes e a busca foi realizada por juizes independentes com a utilização dos descritores "money AND marital finances"; "money AND couples"; "money AND marital interaction"; "money AND marital relationship"; "money AND marital conflict"; "couples AND meaning of money"; "couples AND economic psychology"; "couples AND management of money"; "couples AND financial problems"; "couples AND use of money". A busca gerou o resultado de 1.116 artigos. Para a análise, foram excluídos artigos repetidos, teses, dissertações, resumos e trabalhos que não relacionavam dinheiro e conjugalidade, totalizando 41 artigos. Os resultados revelaram que os conflitos relacionados ao dinheiro ocorrem com mais intensidade no início do casamento e no que antecede a aposentadoria, que os desacordos financeiros são fortes preditores para o divórcio e que o manejo do dinheiro está relacionado com aspectos afetivos e satisfação conjugal.

Palavras-chave: Dinheiro, conjugalidade, revisão sistemática.

\section{Money and Conjugality: A Systematic Literature Review}

\begin{abstract}
This study is a systematic literature review on the existing Brazilian and international scientific production about money and conjugality published from 2004 to 2014. Data bases consulted were PsycINFO, Scientific Electronic Library Online (SciELo), Periódicos Eletrônicos de Psicologia (PePSIC) and Periódicos Capes. Two independent judges searched the bases using the descriptors: "money AND marital finances"; "money AND couples"; "money AND marital interaction"; "money AND marital relationship"; "money AND marital conflict"; "couples AND meaning of money"; "couples AND economic psychology"; "couples AND management of money"; "couples AND financial problems";
\end{abstract}

Endereço para correspondência: Av. Ipiranga, 6681, Partenon, Porto Alegre, RS, Brasil 90619-900. E-mail: luisa.habigzang@pucrs.br. 
"couples AND use of money". The search resulted in 1,116 articles. For the analysis, we excluded repeated articles, theses and dissertations, abstracts, and studies that did not associate money with conjugality, resulting in 41 articles. Results showed that: money-based conflicts occur more intensively in early stages of marriage and before retirement; financial disagreements are strong predictors for divorce; and money management is associated to affect aspects and conjugal satisfaction.

Keywords: Money, conjugality, systematic review.

\section{Dinero y Conyugalidad: Una Revisión Sistemática de la Literatura}

\section{Resumen}

El objetivo de este artículo fue realizar una revisión sistemática de la literatura nacional e internacional sobre la producción científica que existe acerca del tema del dinero y de la conyugalidad, entre el periodo de 2004 a 2014. Se consultaron las bases de datos PsycINFO, Scientific Electronic Library Online (SciELo), Periódicos Eletrônicos de Psicologia (PePSIC) y Periódicos Capes y se hizo una búsqueda a través de jueces independientes, utilizando los descriptores "money AND marital finances"; "money AND couples"; "money AND marital interaction"; "money AND marital relationship"; "money AND marital conflict"; "couples AND meaning of money"; "couples AND economic psychology"; "couples AND management of money"; "couples AND financial problems"; "couples AND use of money". Ésta búsqueda generó un resultado de 1.116 artículos. Para su análisis fueron excluidos aquellos artículos que aparecieron repetidos, tesis de doctorado, trabajos de magister, resúmenes de trabajo que no relacionaban el dinero con la conyugalidad, totalizando de este modo 41 artículos. Los resultados revelaron que los conflictos relacionados al dinero suceden con más intensidad al comienzo del matrimonio y en el periodo anterior a la jubilación; que los acuerdos financieros son fuertes predictores para el divorcio y que el manejo del dinero está relacionado con aspectos afectivos y satisfacción sexual.

Palabras clave: Dinero, conyugalidad, revisión sistemática.

Assuntos referentes ao dinheiro nem sempre são abordados no início da relação amorosa, entretanto são cotidianamente vivenciados ao longo de um relacionamento afetivo. Muitos são os questionamentos advindos de situações que se apresentam ao casal ao longo do desenvolvimento do ciclo vital conjugal e demandarão dos cônjuges a tomada de decisão conjunta. As consequências de tais decisões repercutirão sobre a conjugalidade e não, como antes da união, apenas sobre a individualidade.

Nas relações conjugais na atualidade coexistem o modelo tradicional de relacionamento, em que os papéis de gênero estão definidos socialmente e culturalmente e são reforçados pelas famílias de origem, e o modelo contemporâneo, caracterizado por contornos sociais e culturais menos definidos e que exige dos cônjuges maior flexibilidade na sua relação. No modelo tradicional, o casamento é entendido como indissolúvel, monogâmico e ligado à reprodução. Os papéis de homem e mulher estão claramente definidos: ao homem é delegada uma dimensão pública, valorizada socialmente e com a função de manutenção econômica da família, de virilidade e de uma atitude protetora do núcleo familiar. À mulher é delegada a dimensão privada, menos valorizada socialmente, cabendo a ela preservar sua sexualidade, dedicar-se à maternidade e cuidar do lar com zelo. Por outro lado, no modelo contemporâneo, a mulher busca conquistar mais espaço na vida pública e investe para mostrar-se capaz no mundo profissional, enquanto o homem procura obter credibilidade na esfera doméstica para mostrar-se capaz no mundo dos afetos (Negreiros \& Féres-Carneiro, 2004; Staudt \& Wagner, 2008).

Os papéis de gênero sofrem transformações e no modelo contemporâneo o casamento pode ser estabelecido por meio de uniões formais e 
informais, estando presente a possibilidade do divórcio nos contratos conjugais. Os papéis de homens e mulheres não possuem fronteiras rígidas e previamente definidas, uma vez que ambos os cônjuges têm deveres e privilégios compartilhados. A sexualidade passa a ser desvinculada da reprodução e é esperado que o homem participe no cuidado dos filhos e nas atividades domésticas. Assim como há a expectativa de que a mulher participe nos recursos de manutenção econômica da família. Tais mudanças, inicialmente sutis, foram criando um novo espaço socialmente aceito e validado, voltado para o individualismo crescente nas demais relações familiares e sociais. Na sociedade atual, tende-se a encontrar o sujeito, independentemente do gênero, auto absorvido, competitivo, produtor-consumidor, em uma sociedade na qual viver significa procurar sensações prazerosas e imediatas, seja nas relações públicas ou privadas (Negreiros \& Féres-Carneiro, 2004).

O casamento, apesar de não estar entre os principais projetos de vida para adultos jovens solteiros, continua sendo fonte de desejo (Falcke \& Zordan, 2010). Contudo, ele está ocorrendo mais tarde no ciclo evolutivo vital, tanto para os homens como para as mulheres, e o aspecto idealizado está ficando mais distante. $\mathrm{O}$ amor, apesar de ser considerado importante, não é mais percebido como único, exclusivo, eterno e reconhecido de imediato. As pessoas não têm mais como referencial romântico a expressão "casaram e foram felizes para sempre", e começa-se a utilizar expressões como "casaram e ficaram casados enquanto se sentiam felizes" (Zordan, Falcke, \& Wagner, 2009).

É possível identificar a força do legado familiar na transmissão de valores, crenças, normas e mitos de geração a geração nas mais diversas culturas. Esse processo baseia-se no pressuposto de que todo indivíduo se insere em uma história que já existe antes mesmo dele nascer, à qual ele deve se adaptar e corresponder. Por serem as relações familiares tão marcantes e influentes na vida do sujeito, elas representam a base do comportamento futuro, sem que ele se dê conta da força que possuem em suas escolhas e decisões cotidianas (Carter \& McGoldrick, 2001; Falcke
\& Wagner, 2005; McGoldrick, Gerson, \& Petry, 2012). Existe uma clara influência do modelo conjugal parental sobre a escolha e vivência da conjugalidade dos filhos quando adultos. O casal enfrenta o desafio de compartilhar duas individualidades e uma conjugalidade e, como se não bastasse tal desafio, depara-se com um contexto de mudança social intensa que, por sua vez, também provoca impacto em sua relação conjugal. Isso ocorre num fluxo contínuo, permeado por aprendizagens internalizadas na família de origem acerca de como é ser um casal e pelas demandas externas, por vezes conflitantes (Féres-Carneiro, 1998; Féres-Carneiro \& Diniz-Neto, 2010; Ziviani, Féres-Carneiro, \& Magalhães, 2012).

Um dos aspectos presentes no contexto relacional e existencial dos cônjuges diz respeito às finanças, pois o dinheiro faz parte da trama do relacionamento conjugal (Guimarães, 2007). Quando os cônjuges possuem dificuldade de conciliar significados diferentes do dinheiro, ou possuem objetivos divergentes para usar o seu dinheiro, o conflito pode surgir (Harth, 2013; Moreira, 2002; Moreira \& Tamayo, 1999; Ronchi \& Avellar, 2011; Washburn \& Christensen, 2008). A vida econômica do casal, a forma de manejo do dinheiro, a influência inegável das famílias de origem de ambos os cônjuges, a influência dos aspectos sociais-culturais-religiosos e de gênero são elementos que coexistem no processo de gerenciamento das finanças. Esse processo torna-se mais explícito a partir do casamento, pois o casal terá que decidir como irá equilibrar as entradas e saídas de dinheiro. $\mathrm{O}$ equilíbrio sobre as finanças torna-se mais desafiador se considerarmos que os casais estão imersos num tipo de sociedade caracterizada pelo consumo de bens e serviços abundantes, que podem gerar conflitos e necessidades artificiais. Os conflitos sobre as finanças podem "secretamente minar relacionamentos durante anos" (Madanes \& Madanes, 1997, p. 64). O dinheiro possui um caráter simbólico, um significado permeado por aspectos imperceptíveis no cotidiano, que é construído a partir do universo relacional do indivíduo ao longo do seu desenvolvimento. Neste universo de significados so- 
bre o dinheiro, encontram-se aspectos negativos e positivos.

É notável que coexistam diferenças no significado e no manejo do dinheiro dentro de uma conjugalidade, e assim, necessariamente, há um espaço de diálogo ou de silêncio sobre como cada indivíduo administra, sente e maneja o dinheiro. Existem ditos e não ditos, pois o casal desconhece aspectos intrínsecos e inconscientes relacionados ao universo de símbolos, significados e crenças relacionadas ao dinheiro. Assim, o casal pode deparar-se com manejo e significados próximos e gerar maior harmonia relacionada às finanças, ou deparar-se com manejos e significados divergentes. Nesse caso, pode haver espaços de sofrimento no cotidiano em função de decisões constantes sobre a vida econômica conjugal, ligadas ao como adquirir e/ou ao gastar o dinheiro (Atwood, 2012).

Não é uma tarefa fácil, numa união conjugal, decidir o que é pertencente ao indivíduo e o que é pertencente ao casal (Harth, 2013). A crescente participação da mulher no mercado de trabalho traz mudanças relacionadas às questões de gênero, às diferentes formas de relacionamentos íntimos e às diferentes estratégias de manejo financeiro (Coelho, 2013; Vogler, Brockmann, \& Wiggins, 2006). Além disso, os diferentes modos de coabitação interferem no manejo das finanças. Os casais com união informal tendem a manejar as finanças de forma mais individualizada, tendo contas bancárias separadas, e os casais que são casados legalmente apresentam maior tendência a manejar as finanças de forma compartilhada e a terem contas conjuntas. Tal manejo das finanças indica que quanto maior é o nível de comprometimento na relação afetiva, maior será a troca/ diálogo sobre as finanças (Hiekel, Liefbroer, \& Poortman, 2014; Van der Lippe, Voorpostel, \& Hewitt, 2014; Vogler et al., 2006).

Considerando a relação inerente entre dinheiro e conjugalidade, o objetivo deste estudo foi realizar uma revisão sistemática da produção científica sobre tal relação, a fim de verificar o que e como o tema do dinheiro na conjugalidade tem sido investigado e qual foi o conhecimento produzido na última década.

\section{Método}

Este estudo constitui-se em uma revisão sistemática (Costa \& Zoltowski, 2014) realizada por meio das seguintes etapas: (a) formulação e delimitação da questão de pesquisa; (b) escolha das fontes de dados; (c) eleição das palavras-chave para busca; (d) busca e organização dos resultados; (e) seleção dos artigos pelo resumo, de acordo com os critérios de inclusão e exclusão; (f) extração dos dados dos artigos selecionados; (g) avaliação dos artigos e (h) síntese e interpretação dos dados.

As bases de dados consultadas foram PsycINFO, Scientific Electronic Library Online (SciELo), Periódicos Eletrônicos de Psicologia (PePSIC) e Periódicos Capes, e os descritores utilizados para busca foram: "money AND marital finances"; "money AND couples"; "money AND marital interaction"; "money AND marital relationship"; "money AND marital conflict"; "couples AND meaning of Money"; "couples AND economic psychology"; "couples AND management of money"; "couples AND financial problems"; "couples AND use of money". A busca foi realizada por dois juízes independentes, no mês de janeiro de 2015.

Os artigos encontrados foram analisados com base no título e resumo. Os critérios de inclusão foram: artigos empíricos da área da psicologia, em português, espanhol, inglês e alemão, sem restrição de país de origem, publicados de janeiro de 2004 a dezembro de 2014. Os critérios de exclusão utilizados foram: artigos repetidos em mais de uma base de dados, livros, teses e dissertações, resumos, trabalhos publicados em congressos e estudos que abordavam questões sobre dinheiro ou conjugalidade sem estabelecer relações entre essas variáveis. Após o emprego dos critérios de inclusão e exclusão, os artigos foram lidos cuidadosamente e analisados na íntegra por dois juízes independentes. O conteúdo dos artigos foi organizado e categorizado da seguinte forma: ano de publicação, país de origem do estudo, objetivo principal, delineamento, amostra e principais resultados. Depois da extração das informações, 
as fichas foram comparadas e foram realizadas análises quantitativas e qualitativas dos estudos, buscando a síntese e interpretação dos dados.

\section{Resultados}

A partir dos critérios estabelecidos para busca nesta revisão sistemática, foram recupera- dos 1.116 artigos nas seguintes bases: Periódicos Capes $(n=1.074)$; PsycINFO ( $n=22)$; PePsic $(n=04)$ e SciELO $(n=16)$. Após a aplicação dos critérios de inclusão e exclusão, foram excluídos 1.052 artigos, totalizando uma amostra de 41 estudos incluídos para análise. O fluxograma apresentando o processo de seleção dos estudos está apresentado na Figura 1.

\section{Etapa 1}

Estudos identificados a partir da busca nas seguintes bases de dados

\begin{tabular}{|c|c|c|c|}
\hline Periódicos Capes & PsycINFO & PePsic & SciELO \\
$n=1.074$ & $n=22$ & $\mathrm{n}=04$ & $n=16$ \\
\hline
\end{tabular}

Total de artigos selecionados $=1.116$

\section{Etapa 2}

Aplicação dos critérios de inclusão e exclusão de artigos repetidos $=$ excluídos 1.052

\section{Etapa 3}

Artigos eliminados pelos critérios de exclusão $=23$

Amostra final de artigos $=41$

\section{Etapa 4}

Extração dos dados, síntese e interpretação

Figura 1. Fluxograma das etapas de seleção dos artigos para revisão sistemática.

O ano de publicação, o país de origem do estudo, o delineamento utilizado e os participantes foram analisados quantitativamente, por meio de frequências e porcentagens. Com relação ao ano de publicação identificou-se a seguinte distribuição: 2004 (01 artigo), 2005 (03 artigos), 2006 (01 artigo), 2007 (02 artigos), 2008 (06 artigos), 2009 (05 artigos), 2010 (09 artigos), 2011 (05 artigos), 2012 (05 artigos), 2013 (01 artigo), 2014 (03 artigos).

Os países de origem dos estudos foram: Estados Unidos (19 artigos), Reino Unido (10 arti- gos), Argentina (03 artigos), Brasil (02 artigos), Canadá (02 artigos), Colômbia (01 artigo), Bélgica (01 artigo), Finlândia (01 artigo), Holanda (01 artigo) e Alemanha (01 artigo). O delineamento utilizado nos estudos foi majoritariamente quantitativo (27 artigos, 65,85\%), seguido por estudos qualitativos (13 artigos, 31,71\%) e um estudo com delineamento misto (2,44\%). Por fim, foi verificado que os participantes das pesquisas foram: casais em 21 estudos $(51,22 \%)$, indivíduos sem considerar estado civil em 14 estudos $(34,15 \%)$, coabitantes em três estudos 
(7,32\%), indivíduos casados em dois estudos $(4,88 \%)$, e famílias em um estudo $(2,4 \%)$.

Os objetivos dos estudos foram submetidos à análise de conteúdo (Bardin, 2010). Esta análise foi realizada partir de uma pré-análise dos objetivos dos 41 estudos selecionados, buscando entender a proposta investigativa de cada um deles; posteriormente os objetivos dos estudos foram agrupados por suas semelhanças. Por fim, foram criadas as categorias que representassem este agrupamento. Este processo também foi realizado pelos juízes independentes. Foram identificadas seis categorias:
1. Questão financeira e relação conjugal (05 estudos);

2. Tensão econômica e satisfação conjugal (10 estudos);

3. Manejo do dinheiro e relação conjugal (14 estudos);

4. Percepção do dinheiro e influência na relação conjugal (02 estudos);

5. Qualidade conjugal e recursos econômicos (04 estudos);

6. Outros (06 estudos). A Tabela 1 apresenta os principais objetivos e resultados dos estudos que compuseram cada categoria de análise.

Tabela 1

Caracterização das Principais Categorias de Análise, Objetivos e Resultados

\begin{tabular}{|c|c|c|c|}
\hline $\begin{array}{l}\text { Categoria } \\
\text { de análise }\end{array}$ & $\begin{array}{l}\text { Número } \\
\text { artigos }\end{array}$ & Principais objetivos & Principais resultados \\
\hline
\end{tabular}

Questão

financeira

e relação

Investigar aspectos relacionados a

conjugal

Tensão econômica e satisfação conjugal

Manejo

do dinheiro

e relação

conjugal

Investigar associação entre dívida e satisfação conjugal, padrão de comunicação, tensão econômica e sofrimento conjugal;

Avaliar aspectos relacionados a tensão econômica e agressão psi-

10 cológica, qualidade do relacionamento e problemas de dinheiro, pressões financeiras e vida profissional dos cônjuges;

Analisar casais endividados e aspectos que envolvem a falência.

Avaliar o manejo do dinheiro entre casais homoafetivos, casais heterossexuais, casais coabitantes e casais casados, casais que vivem em casas separadas, casais de primeira união e de uniões reconstituídas, casais ao longo do tempo de ralacionamento;

14 Investigar o manejo independente (IM) ou fundos parciais (PP) em
A percepção de desigualdade financeira e desacordos financeiros são preditores de menores níveis de satisfação conjugal e maior possibilidade de divórcio. casais e os acordos econômicas a partir do manejo escolhido pelos cônjuges assim como as questões que envolvem planos de aposentadoria
As dívidas conjugais foram associadas ao aumento das discussões e diminuição de níveis de satisfação conjugal. As mulheres se envolvem mais na tentativa de resolução dos processo de endividamento e dívidas conjugal causando níveis mais elevados de sofrimento psíquico para elas. As pressões econômicas estão presentes nos processos de aposentadoria e quando a mulher atribuiu responsabilidade pela dificuldade financeira ao marido. Enquanto, quando os cônjuges que possuem satisfação com comunicação, respeito, compromisso e justiça os níveis de conflito financeiro são baixos.

O manejo do dinheiro nos casais de gays e lésbicas priorizou a manutenção de um grau de autonomia financeira individual (contas separadas); os casais heterossexuais no início da relação mantem contas separadas e com o aumento do sentimento de pertencimento a relação apresentaram maior tendência a integrar as contas; os casais coabitantes optam por manter seu dinheiro inteiramente ou parcialmente separado; o manejo do dinheiro se modifica ao longo do tempo de casamento e está correlacionado com características do relacionamento e com o contexto social em que os casais estão inseridos. Se o contexto social for de desigualdade econômica os casais apresentaram inclinação a exercício do mesmo modelo de desigualdade econômica na relação conjugal. 


\begin{tabular}{lccc}
\hline $\begin{array}{c}\text { Categoria } \\
\text { de análise }\end{array}$ & $\begin{array}{c}\text { Número } \\
\text { artigos }\end{array}$ & Principais objetivos & Principais resultados
\end{tabular}

\begin{tabular}{lll}
\hline $\begin{array}{l}\text { Percepção } \\
\text { do dinheiro } \\
\text { e influência } \\
\text { na relação } \\
\text { conjugal }\end{array}$ & $02 \begin{array}{l}\text { Analisar as práticas financeiras } \\
\text { e sua influência na relação assim } \\
\text { como a diversidade de acordos fi- } \\
\text { nanceiros e percepção de proprie- } \\
\text { dade do dinheiro }\end{array}$ \\
& $\begin{array}{l}\text { Examinar associações entre ren- } \\
\text { da, assistência governamental, } \\
\text { acordos financeiros domésticos, } \\
\text { recursos econômicos e qualidade } \\
\text { conjugal. } \\
\text { conjugal } \\
\text { e recursos } \\
\text { econômicos }\end{array}$ & $\begin{array}{l}\text { Investigar qual a influência do noi- } \\
\text { vado e contas bancárias conjuntas } \\
\text { na qualidade da relação em coabi- } \\
\text { tantes. }\end{array}$
\end{tabular}

Explorar os motivos e a frequência de conflitos conjugais; se o aumento da renda estava associada ao casamento e gestação; como a Outros 06 incerteza financeira revela-se nos casais casados e coabitantes; a dinâmica do poder em casais em que a mulher é principal provedora e em casamentos heterossexuais.
A percepção de propriedade do dinheiro influenciou na organização financeira conjugal de forma conjunta ou separada.

A qualidade conjugal e o compromisso com a relação afetiva diminui quando os níveis de dificuldade financeira aumentam, assim como os conflitos conjugais; as contas conjuntas foram associadas a maiores níveis de qualidade conjugal em coabitantes não noivos com contas conjuntas ou coabitantes noivos.

O dinheiro foi elencado como terceiro lugar motivo de conflito conjugal além de filhos, ciúme, sexo e a família de origem dos cônjuges; o poder financeiro da mulher tende a ser diminuído quando excede a renda do marido. $\mathrm{O}$ poder financeiro não fornece poder às mulheres e aos homens igualmente.
Categoria 1. Questão financeira e relação conjugal. Nessa categoria foram incluídos $(1 \mathrm{e}$ 2) estudos que avaliaram o bem-estar financeiro e os desacordos financeiros associados à probabilidade de divórcio (Dew, 2011; Dew, Britt, \& Huston, 2012). Os resultados apontaram que a percepção de desigualdade financeira foi preditora de dissolução da união, e que os desacordos financeiros foram fortes preditores para o divórcio; (3 e 4) Investigaram associações entre discussões sobre dinheiro e manejo dos conflitos conjugais no lar (Britt, Huston, \& Durband, 2010; Papp, Cummings, \& Goeke-Morey, 2009). Estes estudos concluíram que os cônjuges não classificaram o dinheiro como fonte mais frequente de conflitos conjugais no lar. Contudo, os conflitos que envolviam discussões sobre dinheiro foram considerados mais problemáticos, recorrentes e permaneceram sem solução. Além disso, foi verificado que déficits na comunicação conjugal configuraram-se como preditores de discussões sobre dinheiro e que tais discussões estavam associadas a menores níveis de satisfa- ção conjugal; (5) Analisou discussões relacionadas a dinheiro e os relacionamentos conjugais (Britt \& Huston, 2012). Neste estudo foi identificado que questões divergentes relacionadas ao dinheiro foram altamente preditivas de menores níveis de satisfação com o relacionamento e levemente preditivas de divórcio.

Categoria 2. Tensão econômica e satisfação conjugal. Nessa categoria foram inseridos os estudos que: (1) Examinou os mecanismos que correlacionam dívida e satisfação conjugal em recém-casados (Dew, 2008). Os resultados deste estudo evidenciaram que as mudanças causadas por dívidas conjugais em recém-casados estavam correlacionadas à diminuição do tempo que estes casais passavam juntos. Além disso, as dívidas foram associadas ao aumento das discussões sobre dinheiro e diminuição de níveis de satisfação conjugal; (2) Investigou casais severamente endividados antes de abrirem falência (Thorne, 2010) e constatou que, quando o casal enfrenta a iminência da falência financeira, a tarefa de negociação de dívidas, pesquisa e decisão para 
abrir falência ficou sob a responsabilidade das mulheres. Os resultados apontaram que os maridos se eximiram de responsabilidade financeira e esta atitude foi associada a maior sofrimento para as esposas; (3) Verificou relações entre padrão de comunicação, tensão econômica e sofrimento conjugal (Falconier \& Epstein, 2010) e os resultados apontaram que, independentemente do papel de provedora, as mulheres tenderam a passar por mais tensões econômicas do que homens. O padrão de exigência feminino e o retraimento masculino foram associados ao aumento da tensão econômica e do sofrimento conjugal; (4) Investigou a relação entre tensão econômica e agressão psicológica (Falconier, 2010) e identificou que a tensão econômica foi associada a maiores níveis de ansiedade e depressão para ambos os cônjuges. Entretanto, a ansiedade das mulheres e a depressão dos homens foram associadas a maiores níveis de agressão psicológica para ambos os cônjuges; (5) Verificou a relação entre tensão econômica e satisfação conjugal (Falconier \& Epstein, 2010) e constatou que as diferenças de gênero mediaram a relação entre tensão econômica e a satisfação conjugal das mulheres. Os resultados também sugeriram que a tensão financeira esteve associada a comportamentos de maior exigência das mulheres e maior retraimento dos homens no enfrentamento do problema.

Ainda nessa categoria, foram incluídos os seguintes estudos: (6) Investigou como o estresse econômico reflete no ajustamento conjugal (Kinnunen \& Feldt, 2004) e os resultados revelaram que as dificuldades econômicas estiveram ligadas à tensão econômica, ao aumento de sofrimento psicológico e à diminuição no ajustamento conjugal, principalmente da mulher; (7 e 8) verificaram a relação entre dificuldades econômicas e sofrimento conjugal (Dew \& Stewart, 2012; Dew \& Yorgason, 2009) e os resultados indicaram que o modelo de estresse familiar foi significativo para casais em processo de aposentadoria ou com idade para aposentadoria, pois apresentaram maior conflito conjugal e maior pressão econômica. Além disso, a pressão econômica, a dificuldade na comunicação e as questões da história conjugal de cada casal foram associadas ao conflito financeiro. Níveis mais baixos de conflito financeiro foram identificados em cônjuges que relataram satisfação com comunicação, respeito, compromisso e justiça; (9) estudou as pressões financeiras ou do tempo associadas à vida profissional dos cônjuges (Poortman, 2005) e identificou que os casais que enfrentavam mais problemas financeiros foram aqueles em que o marido trabalhava em média menos horas que a mulher durante os primeiros anos do casamento, e que aqueles que passavam menos tempo juntos, tinham maior risco de divórcio; (10) Investigou a associação entre qualidade do relacionamento e problemas de dinheiro (Diamond \& Hicks, 2011) e verificou que, nos casais em que as mulheres atribuíram ao cônjuge a responsabilidade pelos problemas financeiros, por suas dívidas, despesas ou empregos, foram encontrados níveis mais baixos de satisfação conjugal em ambos os cônjuges.

Categoria 3. Manejo do dinheiro e relação conjugal. Nessa categoria foram incluídos os estudos que objetivaram: (1 e 2) Avaliar o manejo do dinheiro entre casais homoafetivos (Burgoyne, Clarke, \& Burns, 2011; Burns, Burgoyne, \& Clarke, 2008). Identificaram que o manejo do dinheiro nestes casais ocorreu em modelo de sistemas de fundos, rendas ou salários separados, e que um grau de autonomia financeira foi um ideal importante nas finanças dos casais de gays e lésbicas; (3) Examinou concepções sobre compromisso e estilos de manejo do dinheiro em casais heterossexuais (Burgoyne, Reibstein, Edmunds, \& Routh, 2010). Os autores constataram que os casais, pouco antes do casamento, têm a tendência de manter suas contas separadas e que, cerca de um ano depois, as concepções sobre compromisso se modificaram e os casais apresentaram maior tendência a tratar o dinheiro como um recurso coletivo; (4) Avaliou a organização financeira de casais coabitantes e casais casados (Vogler et al., 2006). O estudo evidenciou que casais coabitantes possuem mais probabilidade de manter seu dinheiro completamente ou parcialmente separado do que os pares casados.

Ainda nesta categoria foram incluídos estudos que: (5) Analisou práticas financeiras entre manejo independente (IM) ou fundos parciais 
(PP; Ashby \& Burgoyne, 2008). Os autores verificaram que classificar casais com base em acordos financeiros objetivos não fornece uma indicação acurada sobre o padrão de vida de cada cônjuge ou o acesso de cada um ao dinheiro. A relação entre IM ou PP é complexa, pois possui uma variedade de formas, com diferentes implicações para o bem-estar individual, dependendo da noção de propriedade que cada cônjuge possui, da forma como cônjuges percebem seus relacionamentos em termos de permanência, compromisso e ideologia; (6) Avaliou as fronteiras em relação a dinheiro, finanças e consumo em casais categorizados como manejo independente (IM; Evertsson \& Nyman, 2012). Foi evidenciado que as fronteiras nos casais com IM não são tão definidas como sugere o rótulo de IM. Suas práticas de manejo do dinheiro são variadas e complexas não os caracterizando como individualistas, pois em suas práticas de manejo do dinheiro há evidência de flexibilidade nos acordos. (7) Analisou o sistema de manejo do dinheiro em casais ao longo do tempo (Burgoyne, Reibstein, Edmunds, \& Dolman, 2007). Os achados indicaram que as formas de manejo do dinheiro mudam ao longo do tempo de casamento e que os sistemas de manejo independente podem, com o passar do tempo, trazer desigualdades econômicas, caso o casal opte pelo cuidado dos filhos como tarefa feminina; (8) Compreender as estratégias de manejo da renda de casais no Canadá (Laporte \& Schellenberg, 2011). Os resultados mostraram que as estratégias de manejo da renda estão correlacionadas com características do relacionamento (estado de união civil, duração do relacionamento, presença de filhos). O estudo ainda identificou correlações entre manejo da renda independente, nível educacional e quantidade da renda recebida por cônjuges mulheres.

Os estudos (9 e 10) exploraram a individualização dos casais em seus acordos financeiros no Reino Unido (Pahl, 2005, 2008) e descobriram que os casais têm se tornado cada vez mais individualizados em seus acordos financeiros e tal decisão pode criar desigualdade entre cônjuges. A decisão de tais casais em manter finanças separadas foi motivada pelo desejo de igualdade e autonomia; (11) Investigou a organização finan- ceira entre casais que vivem em casas separadas (Lyssens-Danneboom \& Mortelmans, 2014) e os resultados evidenciaram que tais casais apresentavam noções tradicionais de papéis de gênero e vida a dois, mesmo estando em relacionamentos considerados não tradicionais. Os casais que previam a coabitação mostraram mais apoio financeiro mútuo, de modo semelhante a um casamento tradicional, do que aqueles casais que não possuíam perspectiva de coabitação; (12) Analisou sistemas de administração do dinheiro empregados por casais de primeira união e de uniões reconstituídas (Ripoll-Núñez \& Arrieta, 2012). Os resultados revelaram que existem cinco sistemas de administração do dinheiro. São eles: salário completo, mesada, fundo comum, manejo independente e manejo independente com fundo em comum. Os casais de primeira união empregavam sistemas de manejo independente ou sistemas de manejo independente com fundo em comum. Os casais reconstituídos utilizavam principalmente o fundo em comum; (13) Explorou as desigualdades econômicas e seus efeitos na probabilidade de casais terem acordos iguais e/ou desiguais no manejo do dinheiro (Yodanis \& Lauer, 2007). Os resultados indicaram que os casais inseridos em contexto social que pratica e apoia a desigualdade econômica eram mais propensos a praticarem desigualdade econômica entre si; (14) Examinou os efeitos do controle sobre finanças de homens e mulheres e a probabilidade de cada cônjuge contribuir com planos de aposentadoria (Phipps \& Woolley, 2008). Os resultados evidenciaram que as mulheres não investem o dinheiro em poupanças pessoais e tal comportamento pode exacerbar desigualdades conjugais relacionadas às formas de acesso a pensões e/ou poupança.

Categoria 4. Percepção do dinheiro e influência na relação conjugal. Nessa categoria constam os estudos que exploraram: (1) as práticas monetárias de casais heterossexuais e crenças sobre a influência do dinheiro em suas relações (Burgoyne, Clarke, Reibstein, \& Edmunds, 2006) e os resultados evidenciaram que a percepção que os casais possuem sobre a propriedade do dinheiro influenciou como eles organizaram suas finanças como recurso coletivo ou recurso 
privado para cada cônjuge; (2) a relação entre diversidade de acordos financeiros e percepção de propriedade do dinheiro com práticas financeiras (Ashby \& Burgoyne, 2009). Os resultados deste estudo indicaram que as percepções de propriedade do dinheiro como práticas financeiras são um fator definidor da forma como os casais irão manejar o dinheiro de forma conjunta ou separada.

Categoria 5. Qualidade conjugal e recursos econômicos. Essa categoria integrou estudos que: (1) Examinou associações entre renda, assistência governamental e qualidade conjugal (Schramm \& Harris, 2011). Os resultados revelaram que quanto menor a renda conjugal, maior o auxílio governamental e menor a qualidade do relacionamento e o comprometimento dos casais; (2) Avaliou a associação entre acordos financeiros domésticos e qualidade conjugal (Addo \& Sassler, 2010). Os resultados evidenciaram que contas conjuntas foram associadas a maiores níveis de qualidade conjugal e que acordos individualistas alteraram a qualidade conjugal de mulheres, estando associados à redução de sentimentos de intimidade, compatibilidade sexual e satisfação com a resolução de conflitos; (3) Analisou a relação entre recursos econômicos e qualidade da relação entre casais jovens (Halliday Hardie \& Lucas, 2010) e foi verificado que dificuldades econômicas estavam associadas à maior número de conflitos conjugais, tanto em casais casados quanto em casais coabitantes. O fator econômico foi preditor de conflito, independente de casamento oficializado ou de coabitação; (4) Investigou em que medida o noivado e as contas bancárias conjuntas influenciaram a qualidade da relação entre coabitantes (Steuber \& Paik, 2013). Os resultados revelaram que coabitantes não noivos com contas conjuntas apresentaram níveis de qualidade de relacionamento similares aos coabitantes noivos. Entretanto, os namorados que não estavam noivos e não possuíam contas conjuntas apresentaram nível de qualidade de relacionamento mais baixo.

Categoria 6. Outros: Nessa categoria foram incluídos estudos que: (1) Explorou os motivos de conflitos conjugais e a frequência com que ocorrem nas relações conjugais (Mosmann \& Falcke, 2011). Os resultados evidenciaram que um dos motivos mais frequentes de desentendimento entre o casal é o dinheiro (terceiro lugar); (2) Investigou os problemas conjugais comumente enfrentados por casais brasileiros (Miller et al., 2014) e foi verificado que o dinheiro, os filhos, o ciúme, o sexo e a família de origem são os motivos de conflito elencados em ordem de frequência pelos casais; (3) Examinou se a melhora da renda estava associada ao casamento e à criação de filhos (Gibson-Davis, 2009). Os resultados confirmaram a hipótese de que mudanças positivas na renda estão associadas à maior probabilidade de casamento; (4) Explorou a natureza da incerteza financeira e como ela se manifesta nos casais casados ou em coabitação (Romo, 2014) e concluiu que os casais ressaltaram que em períodos de crise econômica a comunicação sobre como ambos percebem as finanças é muito importante para o enfrentamento de tais dificuldades. Foram identificados cinco tipos: incerteza econômica; incerteza administrativa; incerteza pessoal; incerteza comunicacional e incerteza crônica; (5) Investigou a dinâmica do poder em casamentos nos quais as esposas eram a principal provedora (Tichenor, 2005). Os resultados indicaram que mesmo quando a mulher é a principal provedora econômica, seu poder econômico vai sendo minimizado no momento em que sua renda excede a do marido. Com este comportamento o suposto poder masculino é preservado dentro do casamento; (6) Avaliou a influência da renda individual e familiar no poder exercido dentro de casamentos heterossexuais na Alemanha (Lott, 2009). Os resultados indicaram que as desvantagens de poder para mulheres existem independentemente de suas rendas, uma vez que o dinheiro não é um recurso objetivo que forneça poder às mulheres e aos homens igualmente.

\section{Discussão}

A partir da revisão sistemática da literatura verificou-se que as publicações foram oriundas de diferentes países evidenciando o interesse dos pesquisadores sobre o tema na área da Psicologia. A maioria dos estudos foi realizada em países economicamente desenvolvidos, principalmente nos Estados Unidos e Reino Unido. Aspectos 
culturais e econômicos geram influências no manejo e significado atribuído ao dinheiro pelos casais. Verifica-se a necessidade de mais estudos em países economicamente em desenvolvimento para compreender possíveis diferenças culturais.

Cabe destacar que foram identificados apenas dois estudos nacionais nesta revisão sistemática da literatura. Diferentemente dos estudos internacionais que tiveram como objetivo central investigar relações diretas entre conjugalidade e dinheiro, os estudos nacionais tiveram como objetivo central investigar motivos de conflitos entre casais e encontraram, entre seus resultados, que o dinheiro é um motivo frequente de conflitos. O pequeno número de investigações referentes ao contexto brasileiro com foco específico em questões financeiras evidencia a necessidade pesquisas que considerem aspectos culturais e econômicos de nossa realidade.

O predomínio do delineamento quantitativo nos estudos que compuseram a amostra pode ser justificado pelo objetivo de investigar as relações entre conjugalidade e dinheiro com amostras representativas. Entretanto, os instrumentos de autorrelato utilizados podem sofrer influência da desejabilidade social dos respondentes. O dinheiro na conjugalidade é um tema delicado que pode estar associado a conflitos. $\mathrm{O}$ ideal do casamento pode influenciar as respostas. Salienta-se a possibilidade de complementariedade entre os estudos quantitativos e qualitativos com o intuito de aprofundar a percepção dos participantes sobre o tema. Outra escolha metodológica identificada foi a inclusão de casais nas investigações (21 estudos) que permite a análise de elementos da díade conjugal.

Os 41 estudos evidenciaram, de uma maneira geral, que o dinheiro é um elemento importante das relações conjugais, podendo ser fonte de conflito. Ele configura-se como um componente potencialmente significativo, está associado com as dimensões de afeto e compromisso conjugal e pode ser preditor de divórcio. Existe uma maior propensão de conflito, evidenciados pela revisão, no início do casamento e no período que antecede a aposentadoria. Os conflitos relacionados ao manejo do dinheiro no início da relação conjugal estão presentes na literatura, pois ele é um objeto carregado de simbolismos individuais, nem sempre compartilhado na conjugalidade e o início do casamento representa um período de intensos ajustes e adaptações (Borges \& Magalhães, 2009; Capriles, 2005; Madanes \& Madades, 1997). Os conflitos presentes nos anos que antecedem a aposentadoria também são abordados pela literatura (Barbosa \& Traesel, 2013; Bruns \& Abreu, 1997). Neste período do ciclo de vida familiar os cônjuges deparam-se com o resultado do seu investimento na independência financeira e no plano de aposentadoria ao longo de sua trajetória conjugal. No exercício da conjugalidade, os casais estabelecem acordos financeiros e adequam-se às consequências de tais acordos. Parece existir um período de acomodação aos acordos, que se mantêm por anos, e quando o casal depara-se com os resultados oriundos das suas escolhas no período da aposentadoria, as desigualdades de gênero podem potencializar conflitos relacionais (Meirelles \& Souza, 2015).

A desigualdade de gênero foi outro aspecto identificado nos resultados dos estudos. As mulheres parecem sofrer mais prejuizos em relação às questões que envolvem dinheiro no casamento. Elas sentem-se mais tensionadas, apresentam níveis elevados de sofrimento psíquico e se envolvem mais que seus cônjuges na tentativa de resolução da dificuldade econômica. Os cônjuges são influenciados pela cultura e pelo aprendizado social das figuras de provedor e de cuidadora. Ambos contribuem para a manutenção do modelo aprendido e a mulher ainda hoje tende a priorizar o cuidado dos filhos em detrimento da carreira profissional. Assim, ao longo do ciclo de vida conjugal, ela se depara com os prejuízos existenciais e financeiros desta escolha. Enquanto isso, paralelamente instaura-se a exacerbação do individualismo, o que leva à flutuação das identidades pessoais e das relações familiares (Ponciano \& Féres-Carneiro, 2003).

Evidenciou-se uma estreita relação entre satisfação conjugal e finanças. O nível de satisfação conjugal apresenta-se mais elevado quando o nível de conflito relacionado ao dinheiro é menor. Entretanto, os estudos salientam que ocorrem mudanças nos acordos conjugais ao longo do ciclo de vida conjugal. Estas mudanças são 
provenientes das inúmeras situações esperadas $\mathrm{e}$ inesperadas com as quais os casais irão de deparar na vivência de sua história conjugal (Féres-Carneiro, 1998; McGoldrick et al., 2012).

Existe uma complexidade significativa no entendimento do manejo do dinheiro utilizado pelos casais. Não se trata de uma decisão objetiva, mas sim permeada por diferentes significados subjetivos. Os indivíduos buscam maior nível de autonomia financeira quando, de alguma forma, entendem sua relação com um caráter transitório, seja pelas características particulares daquela união ou pelo momento do ciclo de vida da união. Com o passar dos anos de convivência conjugal, com o nascimento dos filhos e, principalmente, com o nível de compromisso afetivo que as pessoas acreditam ter naquela relação, os casais modificam as formas de manejo do dinheiro e sua utilização torna-se um recurso coletivo para os casais (Groisman, 2013; Harth, 2013).

\section{Considerações Finais}

A partir da revisão sistemática da literatura nacional e internacional, no período de 2004 a 2014, objetivando conhecer a pesquisa empírica produzida sobre a temática do dinheiro na conjugalidade, evidenciou-se uma importante relação entre este elemento e a qualidade e satisfação com o casamento. A interface entre dinheiro e conjugalidade é complexa, pois não se configura como uma escolha objetiva e sim permeada pela subjetividade individual, familiar e cultural/ social. As opções feitas pelos casais estão influenciadas pelo contexto social capitalista que pratica e apoia a desigualdade econômica, por meio da desigualdade de gênero, pela concepção de compromisso afetivo que o casal possui, pela etapa do ciclo de vida em que se encontra e pelas experiências de cada indivíduo. Apesar da busca e análise dos estudos por juízes independentes, pode-se considerar a possibilidade dos descritores utilizados não identificarem estudos que relacionassem dinheiro e conjugalidade. Os conflitos conjugais referentes ao dinheiro são mais frequentes no início do ciclo de vida conjugal e nos anos que antecedem a aposentadoria. Tais resultados são significativos para o desenvolvi- mento e promoção de intervenções psicológicas preventivas para os casais.

\section{Referências}

Addo, F. R., \& Sassler, S. (2010). Financial arrangements and relationship quality in low-income couples. Family Relations, 59(4), 408-423. doi:10.1111/j.1741-3729.2010.00612.x

Ashby, K. J., \& Burgoyne, C. B. (2008). Separate financial entities? The Journal of SocioEconomics, 37(2), 458-480. doi:10.1016/j.socec.2006.12.035

Ashby, K. J., \& Burgoyne, C. B. (2009). The financial practices and perceptions behind separate systems of household financial management. The Journal of Socio-Economics, 38(3), 519-529. doi:10.1016/j.socec.2009.02.007

Atwood, J. D. (2012). Couples and money: The last taboo. The American Journal of Family Therapy, 40(1), 1-19. doi:10.1080/01926187.2011.60 0674

Barbosa, T. M., \& Traesel, E. S. (2013). Pré-aposentadoria: Um desafio a ser enfrentado. Barbaroi, (38), 215-234. Recuperado em http:// pepsic.bvsalud.org/scielo.php? script $=$ sci pdf\&pid=S0104-65782013000100012\&lng=pt $\&$ nrm $=\mathrm{iso} \& \mathrm{tlng}=\mathrm{pt}$

Bardin, L. (2010). Análise de conteúdo. Lisboa: Edições 70

Borges, C. D. C., \& Magalhães, A. S. (2009). Transição para a vida adulta: Autonomia e dependência na família. Psico, 40(1), 42-49. Recuperado em http://revistaseletronicas.pucrs.br/ojs/index. php/revistapsico/article/viewFile/3993/4140

Britt, S. L., \& Huston, S. J. (2012). The role of money arguments in marriage. Journal of Family and Economic Issues, 33(4), 464-476. doi:10.1007/ s10834-012-9304-5

Britt, S. L., Huston, S., \& Durband, D. B. (2010). The determinants of money arguments between spouses. Journal of Financial Therapy, 1(1), 4260. doi:10.4148/jft.v1i1.253

Bruns, M. A. D. T., \& Abreu, A. S. (1997). O envelhecimento: Encantos e desencantos da aposentadoria. Revista da ABOP, 1(1), 5-33. Recuperado em http://pepsic.bvsalud.org/scielo.php?script=sci arttext\&pid $=$ S1414-88891997000100002\&lng= pt\&tlng $=\mathrm{pt}$ 
Burgoyne, C. B., Clarke, V., \& Burns, M. (2011). Money management and views of civil partnership in same-sex couples: Results from a UK survey of non-heterosexuals. The Sociological Review, 59(4), 685-706. doi:10.1111/j.1467954x.2011.02032.x

Burgoyne, C. B., Clarke, V., Reibstein, J., \& Edmunds, A. (2006). "All my worldly goods I share with you"? Managing money at the transition to heterosexual marriage. The Sociological Review, 54(4), 619-637. doi:10.1111/j.1467954x.2006.00663.x

Burgoyne, C. B., Reibstein, J., Edmunds, A., \& Dolman, V. (2007). Money management systems in early marriage: Factors influencing change and stability. Journal of Economic Psychology, 28(2), 214-228. doi:10.1016/j.joep.2006.02.003

Burgoyne, C. B., Reibstein, J., Edmunds, A. M., \& Routh, D. A. (2010). Marital commitment, money and marriage preparation: What changes after the wedding? Journal of Community \& Applied Social Psychology, 20(5), 390-403. doi:10.1002/ casp. 1045

Burns, M., Burgoyne, C., \& Clarke, V. (2008). Financial affairs? Money management in same-sex relationships. The Journal of SocioEconomics, 37(2), 481-501. doi:10.1016/j.socec.2006.12.034

Capriles, M. A. (2005). Dinheiro: Sanidade ou loucura. São Paulo, SP: Axis Mundi.

Carter, B., \& McGoldrick, M. (2001). As mudanças no ciclo de vida familiar: uma estrutura para a terapia familiar (2. ed.). Porto Alegre, RS: Artes Médicas.

Coelho, L. (2013). O meu, o teu, o nosso dinheiro: Contributos para o estudo da gestão das finanças conjugais em Portugal. Revista Crítica de Ciências Sociais, (101), 89-110. doi:10.4000/ recs. 5378

Costa, B. A., \& Zoltowski, A. P. C. (2014). Como escrever um artigo de revisão sistemática. In S. H. Koller, M. C. P. P. Couto, \& J. Von Hohendorff (2014), Manual de produção científica (pp. 5570). Porto Alegre, RS: Penso.

Dew, J. (2008). Debt change and marital satisfaction change in recently married couples. Family Relations, 57(1), 60-71. doi:10.1111/j.17413729.2007.00483.x

Dew, J. (2011). Financial issues and relationship outcomes among cohabiting individuals. Family
Relations, 60(2), 178-190. doi:10.1111/j.17413729.2010.00641.x

Dew, J., Britt, S., \& Huston, S. (2012). Examining the relationship between financial issues and divorce. Family Relations, 61(4), 615-628. doi:10.1111/j.1741-3729.2012.00715.x

Dew, J. P., \& Stewart, R. (2012). A financial issue, a relationship issue, or both? Examining the predictors of marital financial conflict. Journal of Financial Therapy, 3(1), 43-61. doi:10.4148/jft. v3i1.1605

Dew, J., \& Yorgason, J. (2009). Economic pressure and marital conflict in retirement-aged couples. Journal of Family Issues, 31(2), 164-188. doi:10.1177/0192513x09344168

Diamond, L. M., \& Hicks, A. M. (2011). "It's the economy, honey!" Couples' blame attributions during the 2007-2009 economic crisis. Personal Relationships, 19(3), 586-600. doi:10.1111/ j.1475-6811.2011.01380.x

Evertsson, L., \& Nyman, C. (2012). Perceptions and practices in independent management: Blurring the boundaries between "mine," "yours" and "ours". Journal of Family and Economic Issues, 35(1), 65-80. doi:10.1007/s10834-012-9348-6

Falcke, D., \& Wagner, A. (2005). A dinâmica familiar e o fenômeno da transgeracionalidade: Definição de conceitos. In A. Wagner (Ed.), Como se perpetua a família? A transmissão dos modelos familiares (pp. 25-46). Porto Alegre, RS: Editora da Pontifícia Universidade Católica do Rio Grande do Sul.

Falcke, D., \& Zordan, E. (2010). Amor, casamento e sexo: Opinião de adultos jovens solteiros. Arquivos Brasileiros de Psicologia, 62(2), 143-155. Recuperado em http://www.redalyc.org/articulo.oa?id=229016553013

Falconier, M. K. (2010). Female anxiety and male depression: Links between economic strain and psychological aggression in Argentinean couples. Family Relations, 59(4), 424-438. doi:10.1111/j.1741-3729.2010.00613.x

Falconier, M. K., \& Epstein, N. B. (2010). Femaledemand/male-withdraw communication in Argentinian couples: A mediating factor between economic strain and relationship distress. Personal Relationships, 18(4), 586-603. doi:10.1111/ j.1475-6811.2010.01326.x

Féres-Carneiro, T. (1998). Casamento contemporâneo: O difícil convívio da individualidade com 
a conjugalidade. Psicologia: Reflexão e Crítica, 11(2), 379-394. Recuperado em http://www.educadores.diaadia.pr.gov.br/arquivos/File/2010/ veiculos_de_comunicacao/PRC/VOL11N2/14. PDF

Féres-Carneiro, T., \& Diniz-Neto, O. (2010). Construção e dissolução da conjugalidade: Padrões relacionais. Paidéia (Ribeirão Preto), 20(46), 269278. doi:10.1590/S0103-863X2010000200014

Gibson-Davis, C. M. (2009). Money, marriage, and children: Testing the financial expectations and family formation theory. Journal of Marriage and Family, 71(1), 146-160. doi:10.1111/j.17413737.2008.00586.x

Groisman, M. (2013). Minha familia e meu dinheiro: A história familiar comanda o seu dinheiro? Rio de Janeiro, RJ: Núcleo-Pesquisas.

Guimarães, C. M. B. (2007). O meu, o seu e o nosso: O processo de construção conjunta do compromisso financeiro do casal de dupla carreira na fase de aquisição do ciclo vital (Dissertação de mestrado, Pontifícia Universidade Católica de São Paulo, SP, Brasil). Recuperado em http:// www.sapientia.pucsp.br/tde_busca/arquivo. php? codArquivo $=4796$

Halliday Hardie, J., \& Lucas, A. (2010). Economic factors and relationship quality among young couples: Comparing cohabitation and marriage. Journal of Marriage and Family, 72(5), 11411154. doi:10.1111/j.1741-3737.2010.00755.x

Harth, J. (2013). O manejo do dinheiro pelo casal e suas implicações na qualidade conjugal (Dissertação de mestrado, Universidade do Vale do Rio dos Sinos, São Leopoldo, RS, Brasil) Recuperado em http://www.unisinos.br/mestrado-e-doutorado/psicologia/teses-e-dissertacoes

Hiekel, N., Liefbroer, A. C., \& Poortman, A. R. (2014). Income pooling strategies among cohabiting and married couples: A comparative perspective. Demographic Research, 30(1), 1527-1560. doi:10.4054/demres.2014.30.55

Kinnunen, U., \& Feldt, T. (2004). Economic stress and marital adjustment among couples: Analyses at the dyadic level. European Journal of Social Psychology, 34(5), 519-532. doi:10.1002/ ejsp. 213

Laporte, C., \& Schellenberg, G. (2011). The income management strategies of older couples in Canada. SSRN Electronic Journal, 38(3-4), 1-22. doi:10.2139/ssrn.2014004
Lott, Y. (2009). Verwaltung und EntscheidungBestimmt das individuelle Einkommen die Machtverteilung in Paarbeziehungen?. KZfSS Kölner Zeitschrift für Soziologie und Sozialpsychologie, 61(3), 327-353. doi:10.1007/s11577009-0071-8

Lyssens-Danneboom, V., \& Mortelmans, D. (2014). Living apart together and money: New partnerships, traditional gender roles. Journal of Marriage and Family, 76(5), 949-966. doi:10.1111/ jomf.12136

Madanes, C., \& Madanes, C. (1997). O significado secreto do dinheiro... e como ele atua nas famílias despertando amor, inveja, compaixão e raiva. Campinas, SP: Editora Psy.

McGoldrick, M., Gerson, R., \& Petry, S. (2012). Genogramas: Avaliação e intervenção familiar (3. ed.). Porto Alegre, RS: Artmed.

Meirelles, V., \& Souza, R. M. (2015). Uso do dinheiro na vida adulta: Uma perspectiva da psicologia clínica e da psicologia do dinheiro. São Paulo, SP: Salta.

Miller, R. B., Nunes, N. A., Bean, R. A., Day, R. D., Falceto, O. G., Hollist, C. S., \& Fernandes, C. L. (2014). Marital problems and marital satisfaction among Brazilian couples. The American Journal of Family Therapy, 42(2), 153-166. doi: 10.1080/01926187.2012.741897

Moreira, A. S. (2002). Dinheiro no Brasil: Um estudo comparativo do significado do dinheiro entre as regiões geográficas brasileiras. Estudos de Psicologia (Natal), 7(2), 379-387. doi:10.1590/ S1413-294X2002000200019

Moreira, A. S., \& Tamayo, A. (1999). Escala de significado do dinheiro: Desenvolvimento e validação. Psicologia: Teoria e Pesquisa, 15(2), 93105. Recuperado em http://www.scielo.br/pdf/ $\mathrm{ptp} / \mathrm{v} 15 \mathrm{n} 2 / \mathrm{a} 02 \mathrm{v} 15 \mathrm{n} 2$

Mosmann, C., \& Falcke, D. (2011). Conflitos conjugais: Motivos e frequência. Revista da SPAGESP, 12(2), 5-16. Recuperado em http://pepsic.bvsalud.org/scielo.php?script=sci_arttext\&p id $=$ S1677-29702011000200002

Negreiros, T. C. D. G. M., \& Féres-Carneiro, T. (2004). Masculino e feminino na família contemporânea. Estudos e Pesquisas em Psicologia, 4(1), 34-47. Recuperado em http://www.e-publicacoes.uerj.br/ojs/index.php/revispsi/article/ view/11109 
Pahl, J. (2005). Individualisation in couple finances: Who pays for the children? Social Policy and Society, 4(4), 381-391. doi:10.1017/ s1474746405002575

Pahl, J. (2008). Family finances, individualisation, spending patterns and access to credit. The Journal of Socio-Economics, 37(2), 577-591. doi:10.1016/j.socec.2006.12.041

Papp, L. M., Cummings, E. M., \& Goeke-Morey, M. C. (2009). For richer, for poorer: Money as a topic of marital conflict in the home. Family Relations, 58(1), 91-103. doi:10.1111/j.17413729.2008.00537.x

Phipps, S., \& Woolley, F. (2008). Control over money and the savings decisions of Canadian households. The Journal of Socio-Economics, 37(2),592-611.doi:10.1016/j.socec.2006.12.042

Ponciano, E. L. T., \& Féres-Carneiro, T. (2003). Modelos de família e intervenção terapêutica. Interações, 8(16), 57-80. Recuperado em http:// pepsic.bvsalud.org/scielo.php?script=sci arttext \&pid=S1413-29072003000200004

Poortman, A. R. (2005). How work affects divorce: The mediating role of financial and time pressures. Journal of Family Issues, 26(2), 168-195. doi:10.1177/0192513x04270228

Ripoll-Núñez, K., \& Arrieta, K. M. (2012). Cuentas conjuntas o separadas: administración del dinero en familias de primera unión y reconstituidas. Summa Psicológica UST (En línea), 9(2), 43-55. Recuperado em http://pepsic.bvsalud. org/scielo.php?script=sci_arttext\&pid=S0719 $-448 \times 2012000200004$

Romo, L. K. (2014). “These Aren't Very Good Times": Financial uncertainty experienced by romantic partners in the wake of an economic downturn. Journal of Family and Economic Issues, 35(4), 477-488. doi:10.1007/s10834014-9389-0

Ronchi, J. P., \& Avellar, L. Z. (2011). Família e ciclo vital: A fase de aquisição. Psicologia em Revista, 17(2), 211-225. Recuperado em http://pepsic. bvsalud.org/pdf/per/v17n2/v17n2a04.pdf

Schramm, D. G., \& Harris, V. W. (2011). Marital quality and income: An examination of the influence of government assistance. Journal of family and economic issues, 32(3), 437-448. doi:10.1007/s10834-010-9212-5

Staudt, A. C. P., \& Wagner, A. (2008). Paternidade em tempos de mudança. Psicologia: Teoria e
Prática, 10(1), 174-185. Recuperado em http:// pepsic.bvsalud.org/scielo.php?pid $=$ S1516$-36872008000100013 \& \mathrm{script}=\mathrm{sci}$ arttext\&tlng=es

Steuber, K. R., \& Paik, A. (2013). Of money and love: Joint banking, relationship quality, and cohabitation. Journal of Family Issues, 35(9), 1154-1176. doi:10.1177/0192513x13503324

Thorne, D. (2010). Extreme financial strain: Emergent chores, gender inequality and emotional distress. Journal of Family and Economic Issues, 31(2), 185-197. doi:10.1007/s10834-010-9189-0

Tichenor, V. (2005). Maintaining men's dominance: Negotiating identity and power when she earns more. Sex Roles, 53(3-4), 191-205. doi:10.1007/ s11199-005-5678-2

Van der Lippe, T., Voorpostel, M., \& Hewitt, B. (2014). Disagreements among cohabiting and married couples in 22 European countries. Demographic Research, 31(1), 247-274. doi:10.4054/demres.2014.31.10

Vogler, C., Brockmann, M., \& Wiggins, R. D. (2006). Managing money in new heterosexual forms of intimate relationships. The Journal of SocioEconomics, 37(2), 552-576. doi:10.1016/j.socec.2006.12.039

Washburn, C., \& Christensen, D. (2008). Financial harmony: A key component of successful marriage relationship. The Forum for Family and Consumer Issues, 13(1).

Yodanis, C., \& Lauer, S. (2007). Economic inequality in and outside of marriage: Individual resources and institutional context. European Sociological Review, 23(5), 573-583. doi:10.1093/esr/jcm021

Ziviani, C., Féres-Carneiro, T., \& Magalhães, A. S. (2012). Pai e mãe na conjugalidade: Aspectos conceituais e validação de construto. Paidéia (Ribeirão Preto), 22(52), 165-175. doi:10.1590/ S0103-863X2012000200003

Zordan, E. P., Falcke, D., \& Wagner, A. (2009). Casar ou não casar?: Motivos e expectativas com relação ao casamento. Psicologia em Revista, 15(2), 56-76. Recuperado em http:// pepsic.bvsalud.org/scielo.php?pid=S1677$-11682009000200005 \& \mathrm{script}=\mathrm{sci}$ arttext\&tlng $=$ es 